\title{
Diffusion tensor imaging revealed different pathological processes of white matter hyperintensities
}

Zhi-gang Min ${ }^{1 \dagger}$, Hai-rong Shan ${ }^{1 \dagger}$, Long Xu', Dai-hai Yuan' Xue-xia Sheng ${ }^{1}$, Wen-chao Xie', Ming Zhang ${ }^{2}$, Chen Niu², Tahir Mehmood Shakir ${ }^{2}$ and Zhi-hong Cao ${ }^{1^{*}}$ (i)

\begin{abstract}
Background: Although increasing evidence showed the correlations between white matter hyperintensities (WMHs) and cognitive impairment, the relationship between them is still modest. Many researchers began to focus on the variation caused by the heterogeneity of $\mathrm{WMH}$. We tried to explore the pathological heterogeneity in $\mathrm{WMH}$ by using diffusion tensor imaging (DTI), so as to provide a new insight into the future research.

Methods: Diffusion weighted images (DWIs) of the brain were acquired from 73 patients with WMH and 18 healthy controls, which were then modeled by DTI. We measured fractional anisotropy (FA), mean diffusivity (MD), axial diffusivity (AD), and radial diffusivity (RD) of white matter of the periventricular frontal lobe ( $\mathrm{pFL}$ ), periventricular occipital lobe $(\mathrm{pOL})$, periventricular parietal lobe $(\mathrm{pPL})$ and deep centrum ovales $(\mathrm{dCO})$, and grouped these measures according to the Fazekas scale. Then we compared the DTI metrics of different regions with the same Fazekas scale grade.

Results: Significantly lower FA values (all $p<0.001$ ), and higher MD (all $p<0.001$ ) and RD values (all $p<0.001$ ) were associated with $\mathrm{WMH}$ observed in the periventricular frontal lobe $(\mathrm{pFL})$ compared to all other regions with the same Fazekas grades. The AD of WMH in the $\mathrm{PFL}$ was higher than that of $\mathrm{PPL}$ and $\mathrm{dCO}$, but the differences between groups was not as high as of MD and RD, as indicated by the effect size. In the normal control group, DTI metrics between $\mathrm{pFL}$ and other regions were not significantly different or less significant different. The difference of DTI metrics of WMH between $\mathrm{PPL}, \mathrm{pOL}$ and $\mathrm{dCO}$ was lower than that of normal white matter, as indicated by the effect size.
\end{abstract}

Conclusion: Distinct pathological processes can be revealed by DTI between frontal periventricular WMH and other regions. These processes may represent the effects of severe demyelination within the frontal periventricular $\mathrm{WMH}$.

Keywords: White matter hyperintensities, Diffusion tensor imaging, Pathological processes

\footnotetext{
* Correspondence: profczh@gmail.com

'Zhi-gang Min and Hai-rong Shan contributed equally to this work. 'Department of Radiology, The Affiliated Yixing Hospital of Jiangsu

University, NO.75 Tongzhenguan Road, Yixing, Jiangsu Province 214200, P.R.

China

Full list of author information is available at the end of the article
}

(c) The Author(s). 2021 Open Access This article is licensed under a Creative Commons Attribution 4.0 International License, which permits use, sharing, adaptation, distribution and reproduction in any medium or format, as long as you give appropriate credit to the original author(s) and the source, provide a link to the Creative Commons licence, and indicate if changes were made. The images or other third party material in this article are included in the article's Creative Commons licence, unless indicated otherwise in a credit line to the material. If material is not included in the article's Creative Commons licence and your intended use is not permitted by statutory regulation or exceeds the permitted use, you will need to obtain permission directly from the copyright holder. To view a copy of this licence, visit http://creativecommons.org/licenses/by/4.0/ The Creative Commons Public Domain Dedication waiver (http://creativecommons.org/publicdomain/zero/1.0/) applies to the data made available in this article, unless otherwise stated in a credit line to the data. 


\section{Background}

White matter hyperintensities (WMHs), which appear hyperintense on T2-weighted imaging (T2WI) or fluid-attenuated inversion recovery (FLAIR) images, are common findings on magnetic resonance imaging (MRI) in elderly people. The prevalence of WMH increases with age and reaches $90 \%$ in the general population over 80 years old [1]. They are usually attributed to chronic small vessel ischemia. Although with similar signals on FLAIR or T2WI, their pathologic changes are heterogeneous, which include myelin pallor, enlargement of perivascular spaces, discontinuity of ependyma, infarctions, gliosis, and axonal loss [2-5]. Existing evidence shows WMH severity is associated with the risk of dementia in the general population [6]. The two most commonly-used methods for evaluating WMH severity are qualitative grading scales and quantitative WMH volumetric measurements [7, 8]. Fazekas et al. [7] categorized periventricular WMHs into three grades. Moderate and severe (grades 2 and 3) periventricular WMHs are believed to be related to ischemia, whereas mild (grade 1) periventricular WMHs are considered nonischemic, mainly due to a partial loss of the ependymal lining [8]. However, correlations between the volume of WMHs and cognitive performance are modest, and many clinical variations cannot be explained by volumetric measures [9].

Most of the recent research showed that lesions location might be another important factor affecting cognition $[10,11]$. In the frontal lobe, parieto-occipital lobe, and other parts of the brain, periventricular WMHs are involved in cognitive impairment $[9,10,12,13]$. Carnevale et al. [10] found that alterations in specific white matter fiber-tracts are related to impaired cognition. Abnormal anterior thalamic radiation appears related to impaired memory, and the forceps minor seems to be involved in processing speed. Cremers et al. [11] suggested that the identification of tract-specific microstructural changes is helpful for understanding the mechanisms of cognitive impairment. Some studies have found that the periventricular WMHs are significantly associated with various cognitive functions, and other studies showed that subcortical WMHs are also involved; while few other studies found no associations $[14,15]$.

The heterogeneity of WMHs might explain why some clinical variations cannot be determined by volumetric measures of WMH [4, 16, 17]. Habes et al. [12] supported the hypothesis that different underlying pathophysiologic mechanisms influenced regional patterns of WMH distribution; they found that frontal WMHs are more strongly associated with blood pressure and cortical atrophy, while only dorsal WMHs are associated with genetic risk factors for Alzheimer s disease. However, little is known about the pathological bases of these WMHs.

Diffusion tensor imaging (DTI) is a unique tool for identifying microstructural white matter changes in vivo and may be able to characterize pathological substrates of WMH since it can detect the abnormality of white matter sensitively [18].. Studies using DTI and magnetization transfer imaging found a difference between frontal and parieto-occipital periventricular WMHs $[19,20]$.

We therefore hypothesized that WMHs that arose from different pathological processes would undergo different microstructural changes that could be detected by DTI. This study aimed to verify the pathological heterogeneity of WMHs by comparing DTI metrics, obtained from different brain regions, using the same grading scale. We additionally investigated microstructural changes in these brain regions.

\section{Methods}

\section{Participants}

The participants were local community-dwelling individuals. Our institutional review board approved this

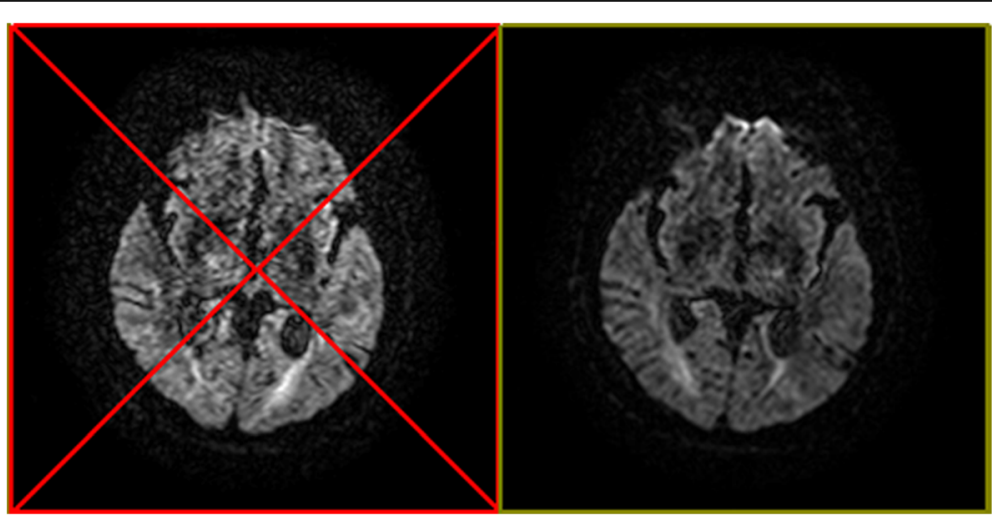

Fig. 1 Corrupted images will be eliminated with automatic outlier slice rejection if its error-area is bigger than $3 \%$. Left image with red " $X$ " were excluded as corrupted image 

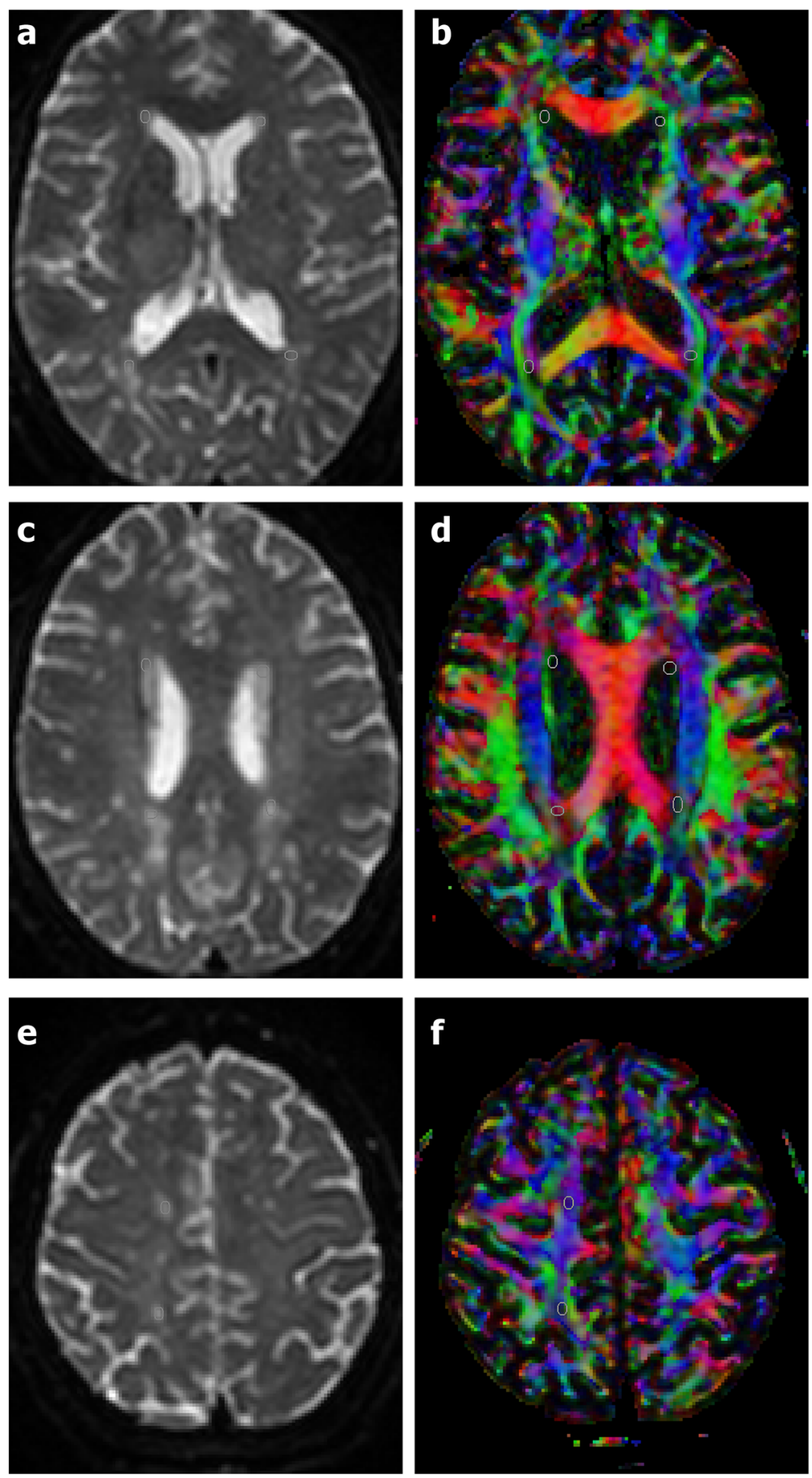

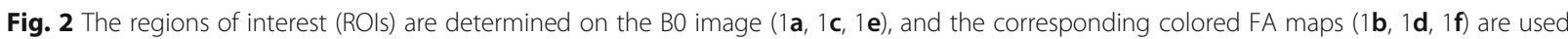
to observe whether the ROls are located in the same white matter bundle. ROls of the periventricular frontal lobe (pFL) were located in the anterior thalamic radiation and superior fronto-occipital fasciculus. ROls of the periventricular occipital lobe (pOL) were located in the tapetum and the posterior region of corona radiata. ROls of the periventricular parietal lobe ( $\mathrm{PPL}$ ) were located in the junction of corpus callosum and parietal superior region of internal capsule. ROls of deep white matter of centrum ovale (dCO) were located in the centrum ovale of frontal lobe and parietal lobe respectively 


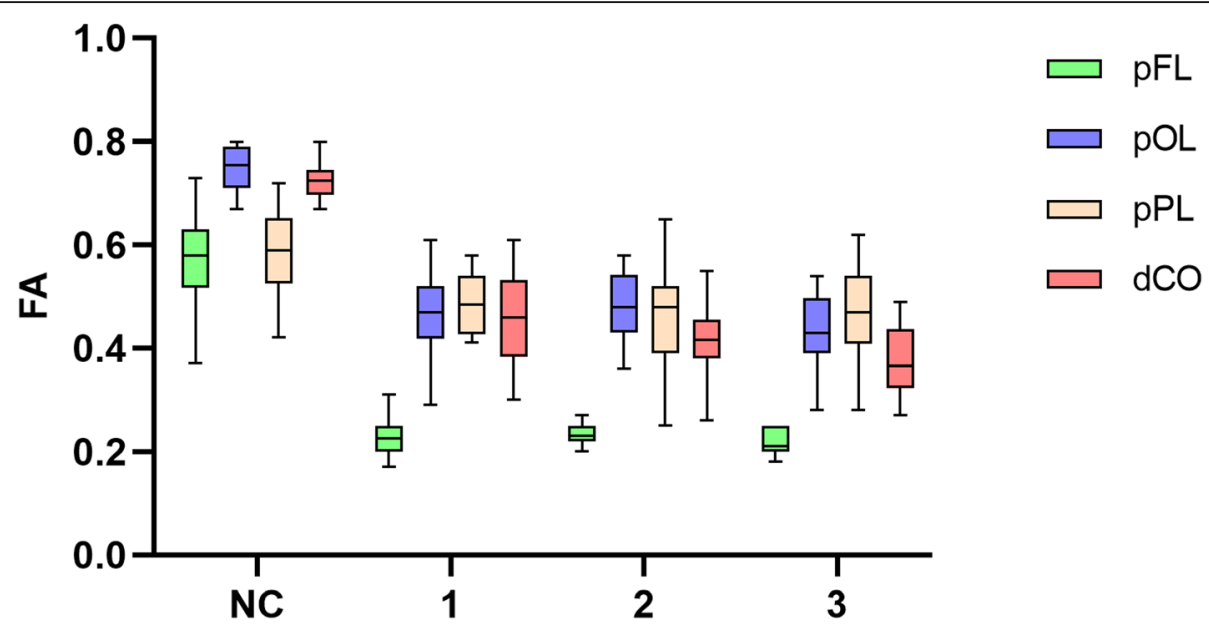

Fazekas Scale

Fig. 3 Box plot of FA with normal control and Fazekas scale 1-3 in different regions

prospective study and written informed consent was acquired from each patient. Patients with WMHs confirmed by FLAIR or T2WI results were recruited. The exclusion criteria were: 1) infarction, tumor, encephalitis and other diseases affected white matter; 2) blurred images due to severe motion artifacts. Twenty-four patients with other lesions and 4 patients with severe motion artifacts were excluded. Finally, a total of 73 patients with WMHs were included in this study. There were 42 male and 31 female patients, with an average age of 72.6 years. We additionally recruited 18 (10 male, 8 female) healthy volunteers, with normal white matter with a Fazekas scale of 0. The average age of control group was 65.4 years. The
Fazekas scale was adopted to classify periventricular and deep WMHs as grades 1, 2, or 3. In periventricular white matter, "caps" or pencil-thin lining WMH were classified as grade 1, smooth "halo" WMH were classified as grade 2 and irregular WMH extending into the deep white matter were classified as grade 3; in deep white matter punctate foci WMH were classified as grade 1, beginning confluence of foci WMH were classified as grade 2 and large confluent areas were classified as grade 3 [7]. All grades were calculated separately from areas within the frontal and parietal-occipital lobes. Two neuro-radiologists assessed each patient, and conflicting results were discussed until an agreement was made.

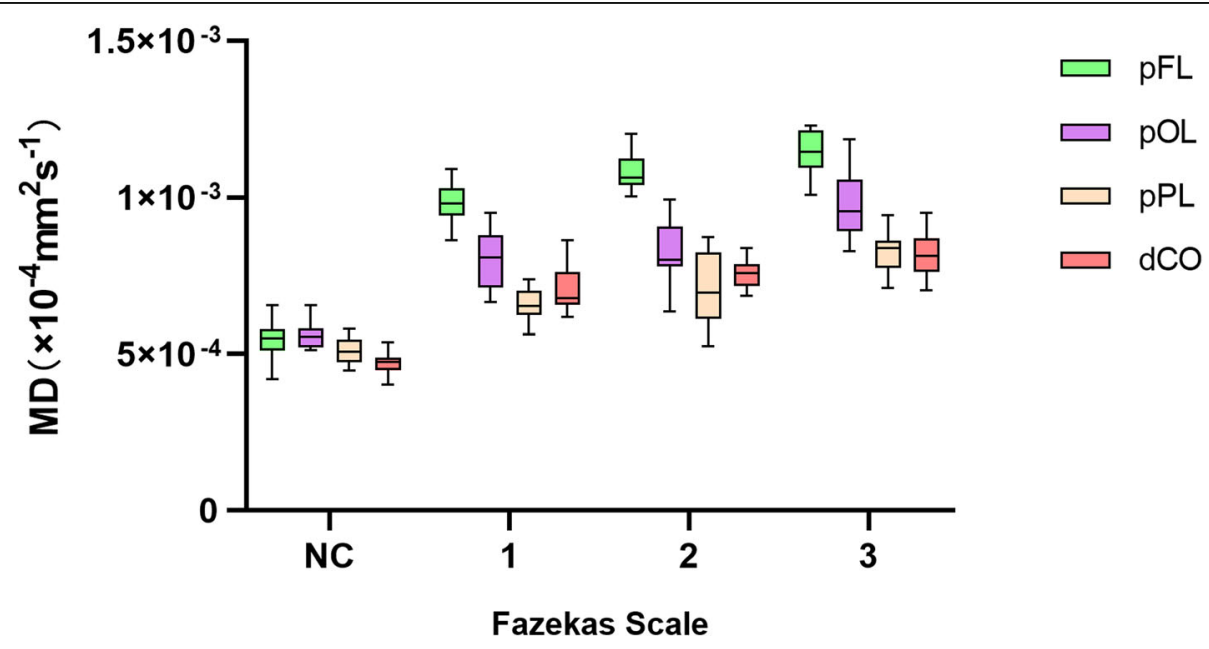

Fig. 4 Box plot of MD with normal control and Fazekas scale 1-3 in different regions 


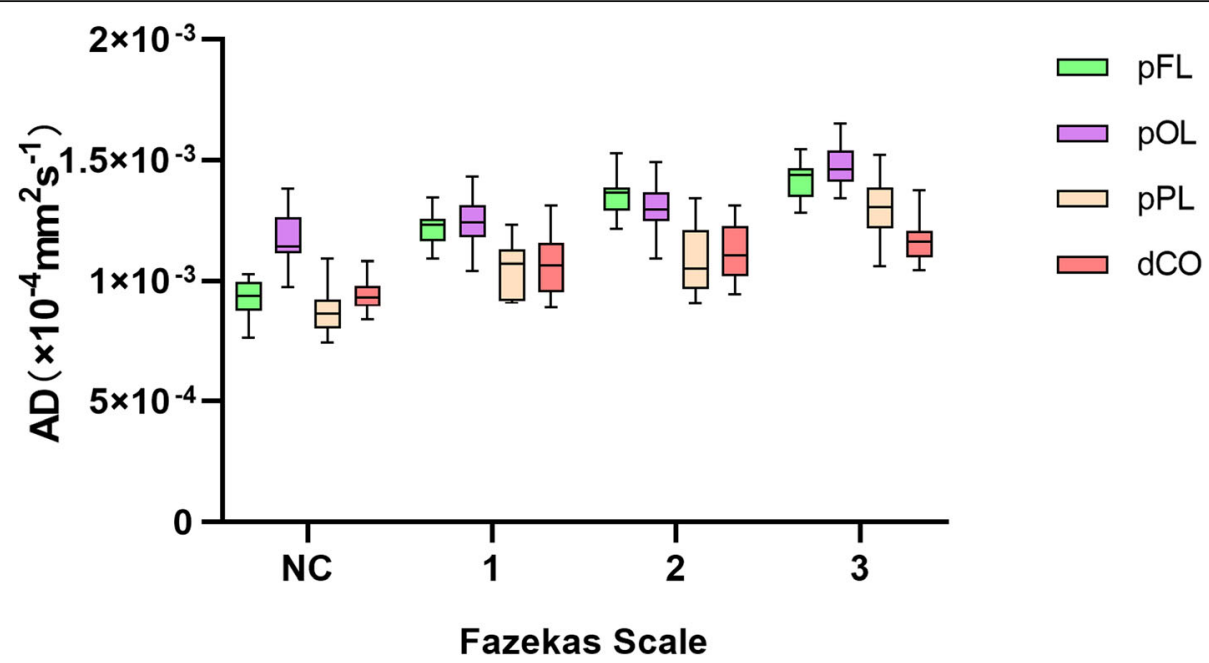

Fig. 5 Box plot of DA with normal control and Fazekas scale 1-3 in different regions

\section{DTI and post-processing}

Diffusion weighted images (DWIs) were acquired from all patients and controls using a 3.0-T MR scanner (Philips Achieva, Best, the Netherlands) equipped with a 16-channel head-neck phased array coil. The imaging parameters were as follows: slice thickness of $2 \mathrm{~mm}$ with no gaps, repetition time of $8000 \mathrm{~ms}$, echo time of $87 \mathrm{~ms}$, field-of-view $228 \mathrm{~mm} \times 228 \mathrm{~mm}, 32$ DWIs (b-values $=1000 \mathrm{~s} / \mathrm{mm}^{2}$ ) with diffusion gradients along different directions and 1 non-DWIs $(\mathrm{b}$-value $=$ 0 ) were acquired, an acquisition matrix of $112 \times 112$ was interpolated to an image matrix of $224 \times 224$. A total of 60 consecutive slices were acquired over 6 min. The raw data are exported to DTIStudio (Johns Hopkins University; https://www.mristudio.org/) [21].
Using the Automated Image Registration (AIR) tool, we used an affine warp model to correct image distortions due to eddy currents and misregistration errors due to head motion. After AIR-based image coregistration, rotational operation is extracted and the orientation of the b-vectors was corrected. Then tensor was estimated with linear least square fitting, automatic outlier slice rejection was performed with relative error $>3 \%$ to eliminate the corrupted images of error area more than 3\%. Exclusion of corrupted images (with red " $\mathrm{X}$ " in the inspection window) can be verified with "Original View" (Fig. 1). Maps of fractional anisotropy (FA), mean diffusivity (MD), axial diffusivity (AD) and radial diffusivity (RD) maps were calculated.

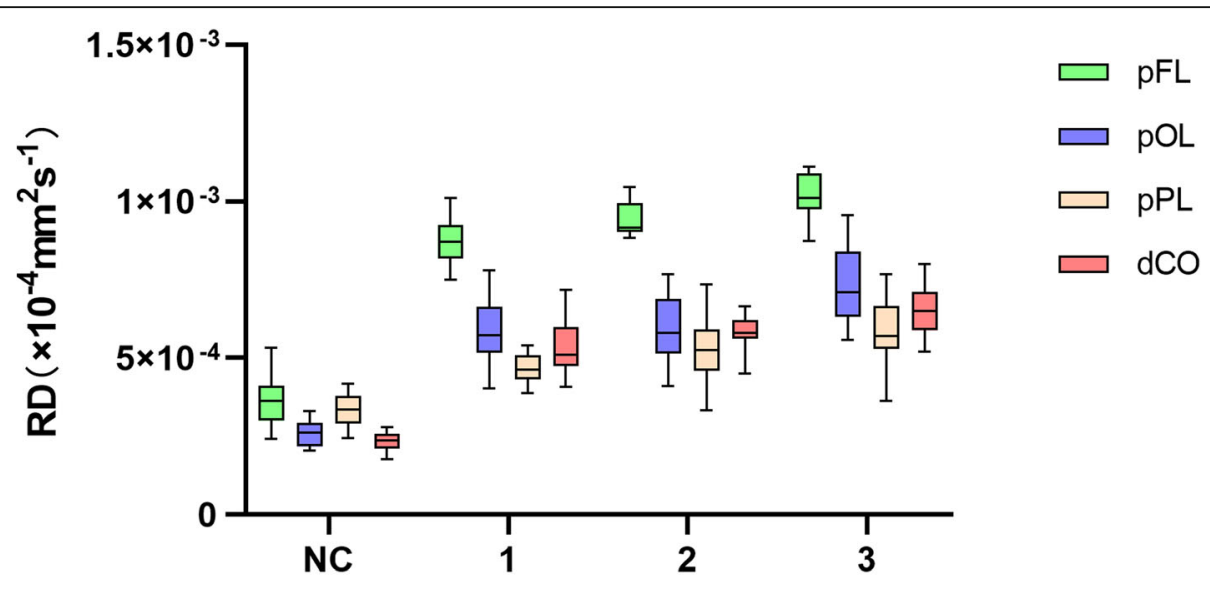

Fazekas Scale

Fig. 6 Box plot of RD with normal control and Fazekas scale 1-3 in different regions 
Table 1 Correlation coefficients between DTI metrics and Fazekas scale in different regions

\begin{tabular}{lllll}
\hline & pFL & pOL & pPL & dCO \\
\hline FA & -0.525 & -0.648 & -0.417 & -0.728 \\
MD & 0.864 & 0.823 & 0.861 & 0.836 \\
AD & 0.891 & 0.749 & 0.831 & 0.666 \\
RD & 0.822 & 0.768 & 0.756 & 0.811 \\
\hline
\end{tabular}

$\overline{p \text {-value all }<0.001 . p F L \text { periventricular frontal lobe, } p O L \text { periventricular occipital }}$ lobe, $P P L$ periventricular parietal lobe, $d C O$ deep centrum ovale

\section{Measurements}

The FA, MD, AD, and RD values of $\mathrm{WMH}$ were measured with regions of interest (ROIs) in three periventricular regions including frontal, occipital and parietal lobes, as well as the deep centrum ovales. These areas were the most common locations of WHMs. According to the range of lesions, 2-4. ROIs were determined, and the average value was calculated. The same DTI metrics in the healthy control group were also measured in the identical white matter tract, which was controlled by using colored FA maps (Fig. 2). Mean diffusion-weighted imaging maps were used to keep the cerebral spinal fluid outside the ROI.

\section{Statistical analysis}

All statistical analyses were performed using SPSS software (version 22, IBM, Armonk, NY, USA), and two-sided $p$ values $<0.05$ indicated a significant difference. Spearman correlation analysis was used to explore the relationship between DTI parameters and Fazekas scale scores. We used univariate analysis of variance (ANOVA) process of the general linear model to identify differences of FA, MD, AD, and RD values in WMH with the same Fazekas grade among regions of periventricular frontal lobe ( $\mathrm{pFL}$ ), periventricular occipital lobe ( $\mathrm{pOL})$, periventricular parietal lobe (pPL) and deep centrum ovales (dCO). Sex and age were used as covariates. Multiple comparisons were performed and corrected with Bonferroni. We calculated $\eta^{2}$ as effect sizes (ES) of ANOVA and Hedges'g as effect sizes of multiple comparison. Box plots were generated by using GraphPad Prism 8.0 (GraphPad Software Inc., San Diego, CA, USA).

\section{Results}

There were 86 WMHs of Fazekas grades 1 in 46 patient, 64 WMHs of Fazekas grades 1 in 35 patients and 86 WMHs of Fazekas grades 3 in 28 patients. With increasing Fazekas grades, the DTI metrics of WMHs in different regions showed similar changes. FA values decreased, while $\mathrm{MD}, \mathrm{AD}$ and $\mathrm{RD}$ values increased as the Fazekas grade increased (Figs.3, 4, 5, and 6). Spearman correlation analysis showed that FA, MD, AD, and $\mathrm{RD}$ values in all regions were significantly correlated $(p<0.001)$ with Fazekas grades (Table 1$)$. However, there are some differences in the correlation coefficients among pFL, pOL, pPL and dCO.

Although DTI metrics in different regions showed similar changes, they don't change at the same rate. FA, MD, $\mathrm{AD}$ and $\mathrm{RD}$ values of $\mathrm{pFL}$ showed more rapid changes from Fazekas scale 0 to 1 than other regions (Figs. 3, 4, 5 and 6). In normal control group, FA values of $\mathrm{pFL}$ were significantly lower than that of pOL $(p<0.001, \mathrm{ES}=2.47)$ and $\mathrm{dCO}(p<0.001, \mathrm{ES}=$ 2.22), but had no significant difference with pPL. However, FA values of the WMH with Fazekas scale 1 of pFL were significantly lower than pOL $(p<0.001, \mathrm{ES}=4.20), \mathrm{pPL}(p<0.001, \mathrm{ES}=6.55)$ and $\mathrm{dCO}(p<0.001, \mathrm{ES}=3.65)$ all (Table 2). Similarly, MD and RD of the WMH with Fazekas scale 1 of pFL were significantly higher than that of all other three regions (Fig. 7). Though MD of normal white matter of pFL was only higher than $\mathrm{dCO}$, and RD of normal white matter of pFL was only higher than pOL and $\mathrm{dCO}$ (Tables 3 and 5). In pFL, the increase of $\mathrm{AD}$ was lower than that of $\mathrm{RD}$ and $\mathrm{MD}$, and it didn't exceed pOL in Fazekas 1 (Table 3). Results of DTI metrics of WMH with grade 2 and 3 between pFL and other regions were same as those of grade 1 (Tables 2, 3, 4, and 5) (Figs. 8 and 9).

The difference of DTI metrics of WMH between pPL, pOL and $\mathrm{dCO}$ was lower than that of normal white matter. In normal white matter, FA values of $\mathrm{pPL}$ were significantly lower than that of pOL $(p<0.001, \mathrm{ES}=2.36)$ and $\mathrm{dCO}(p<0.001, \mathrm{ES}=2.08)$. There was no significant difference in FA of WMH between pPL, pOL and dCO except for the WMH with Fazekas scale 3 between pPL and $\mathrm{dCO}(p<0.001, \mathrm{ES}=1.20)$. MD of normal white

Table 2 Comparison of FA values of normal white matter or WMH with same Fazekas scale in different regions

\begin{tabular}{lllllll}
\hline & $\begin{array}{l}\text { pFL } \\
\text { Mean } \pm \text { SD }\end{array}$ & $\begin{array}{l}\text { pOL } \\
\text { Mean } \pm \text { SD }\end{array}$ & $\begin{array}{l}\text { pPL } \\
\text { Mean } \pm \text { SD }\end{array}$ & $\begin{array}{l}\text { dCO } \\
\text { Mean } \pm \text { SD }\end{array}$ & p-value & Effect Size $\left(\boldsymbol{\eta}^{2}\right)$ \\
\hline Normal white matter & $0.56 \pm 0.10$ & $0.75 \pm 0.04^{* *}$ & $0.59 \pm 0.08$ & $0.72 \pm 0.04^{* *}$ & $<0.001$ & 0.566 \\
WMH of Fazekas scale 1 & $0.22 \pm 0.04$ & $0.46 \pm 0.09^{* *}$ & $0.49 \pm 0.06^{* *}$ & $0.45 \pm 0.09^{* *}$ & $<0.001$ & 0.762 \\
WMH of Fazekas scale 2 & $0.23 \pm 0.02$ & $0.48 \pm 0.07^{* *}$ & $0.46 \pm 0.10^{* *}$ & $0.41 \pm 0.08^{* *}$ & $<0.001$ & 0.720 \\
WMH of Fazekas scale 3 & $0.21 \pm 0.03$ & $0.43 \pm 0.07^{* *}$ & $0.47 \pm 0.10^{* *}$ & $0.39 \pm 0.11^{* *}$ & $<0.001$ & 0.681 \\
\hline
\end{tabular}

$p F L$ periventricular frontal lobe, $p O L$ periventricular occipital lobe, $p P L$ periventricular parietal lobe, $d C O$ deep centrum ovale. There was significant difference compared with $\mathrm{pFL},{ }^{*} p<0.05,{ }^{* *} p<0.001$ 

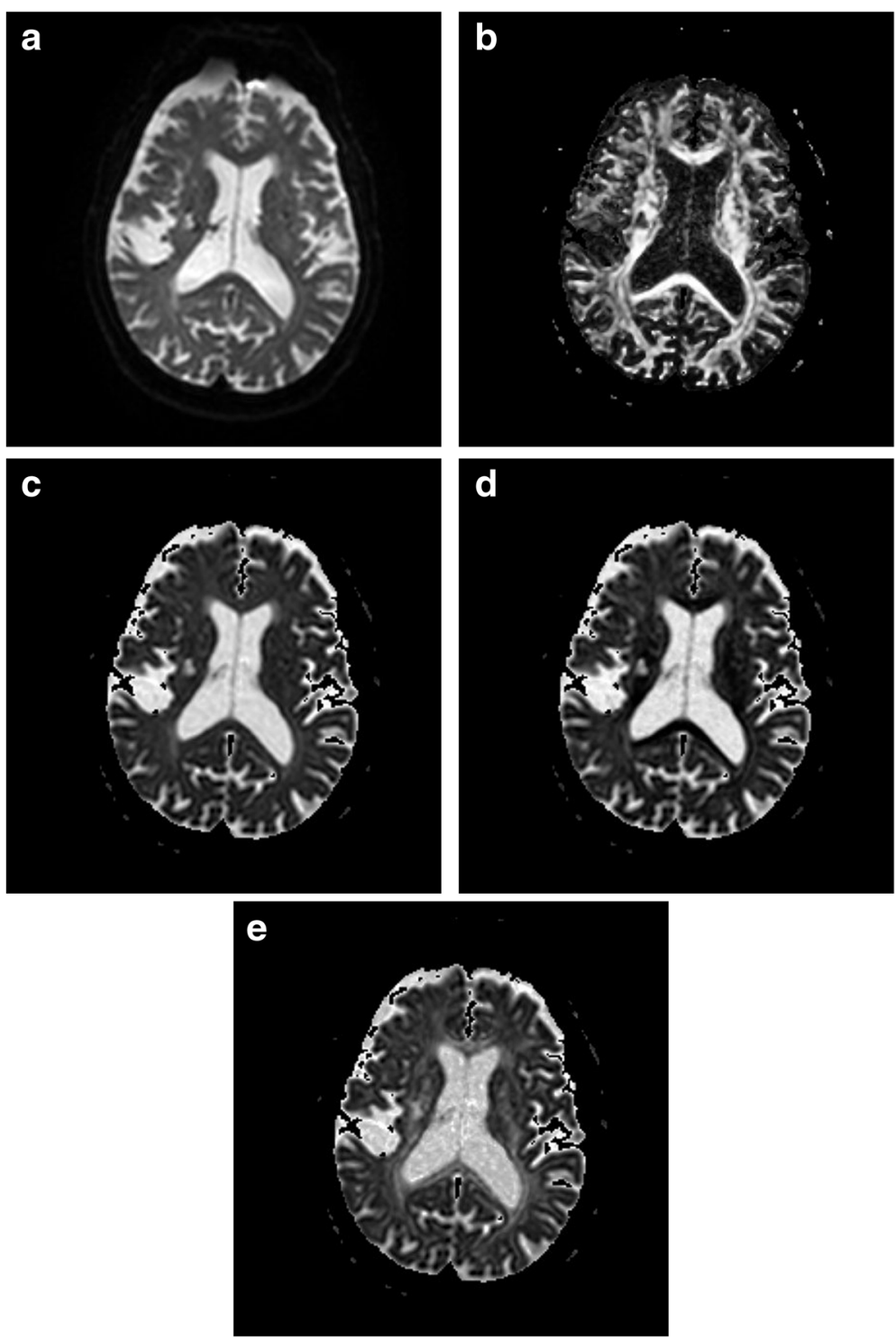

Fig. 7 The bo of the DWI (a) of a 75 years old male showed WMH (Fazekas scale 1) in the pFL, pOL, pPL and dCO. FA (b) of WMH in the pFL are lower than that of $\mathrm{pOL}, \mathrm{pPL}$ and $\mathrm{dCO} . \mathrm{MD}(\mathbf{c})$ and $\mathrm{RD}(\mathbf{d})$ of $\mathrm{WMH}$ in the $\mathrm{pFL}$ are higher than that of $\mathrm{pOL}, \mathrm{pPL}$ and $\mathrm{dCO}$. AD (e) of WMH in the $\mathrm{pFL}$ are close to that of $\mathrm{pOL}, \mathrm{pPL}$ and $\mathrm{dCO}$

Table 3 Comparison of MD values $\left(\times 10^{-4} \mathrm{~mm}^{2} \mathrm{~s}^{-1}\right)$ of normal white matter or WMH with same Fazekas scale in different regions

\begin{tabular}{lllllll}
\hline & $\begin{array}{l}\text { pFL } \\
\text { Mean } \pm \text { SD }\end{array}$ & $\begin{array}{l}\text { pOL } \\
\text { Mean } \pm \text { SD }\end{array}$ & $\begin{array}{l}\text { pPL } \\
\text { Mean } \pm \text { SD }\end{array}$ & $\begin{array}{l}\text { dCO } \\
\text { Mean } \pm \text { SD }\end{array}$ & p-value & Effect Size (n2) \\
\hline Normal white matter & $5.48 \pm 0.58$ & $5.62 \pm 0.48$ & $5.11 \pm 0.40$ & $4.69 \pm 0.31^{* *}$ & $<0.001$ & 0.436 \\
WMH of Fazekas scale 1 & $9.87 \pm 0.57$ & $8.03 \pm 0.84^{* *}$ & $6.59 \pm 0.55^{* *}$ & $7.08 \pm 0.71^{* *}$ & $<0.001$ & 0.762 \\
WMH of Fazekas scale 2 & $10.81 \pm 0.56$ & $8.25 \pm 0.96^{* *}$ & $7.13 \pm 1.05^{* *}$ & $7.55 \pm 0.47^{* *}$ & $<0.001$ & 0.797 \\
WMH of Fazekas scale 3 & $11.48 \pm 0.71$ & $9.81 \pm 1.00^{* *}$ & $8.28 \pm 0.68^{* *}$ & $8.20 \pm 0.66^{* *}$ & $<0.001$ & 0.691 \\
\hline
\end{tabular}

$p F L$ periventricular frontal lobe, $p O L$ periventricular occipital lobe, $p P L$ periventricular parietal lobe, $d C O$ deep centrum ovale. There was significant difference compared with $\mathrm{pFL},{ }^{*} p<0.05,{ }^{* *} p<0.001$ 
Table 4 Comparison of AD values $\left(\times 10^{-4} \mathrm{~mm}^{2} \mathrm{~s}^{-1}\right)$ of normal white matter or WMH with same Fazekas scale in different regions

\begin{tabular}{lllllll}
\hline & $\begin{array}{l}\text { pFL } \\
\text { Mean } \pm \text { SD }\end{array}$ & $\begin{array}{l}\text { MOL } \\
\text { Mean } \pm \text { SD }\end{array}$ & $\begin{array}{l}\text { pPL } \\
\text { Mean } \pm \text { SD }\end{array}$ & $\begin{array}{l}\text { dCO } \\
\text { Mean } \pm \text { SD }\end{array}$ & p-value & Effect Size (n2) \\
\hline Normal white matter & $9.11 \pm 0.82$ & $11.70 \pm 1.15^{* *}$ & $8.63 \pm 0.84$ & $9.41 \pm 0.64$ & $<0.001$ & 0.518 \\
WMH of Fazekas scale 1 & $12.16 \pm 0.62$ & $12.37 \pm 1.12$ & $10.44 \pm 1.19^{* *}$ & $10.62 \pm 1.23^{* *}$ & $<0.001$ & 0.438 \\
WMH of Fazekas scale 2 & $13.48 \pm 0.71$ & $12.96 \pm 1.03$ & $10.92 \pm 1.41^{* *}$ & $11.18 \pm 1.14^{* *}$ & $<0.001$ & 0.506 \\
WMH of Fazekas scale 3 & $14.10 \pm 0.78$ & $14.76 \pm 0.91$ & $12.96 \pm 1.32^{*}$ & $11.57 \pm 0.75^{* *}$ & $<0.001$ & 0.556 \\
\hline
\end{tabular}

$p F L$ periventricular frontal lobe, $p O L$ periventricular occipital lobe, $p P L$ periventricular parietal lobe, $d C O$ deep centrum ovale. There was significant difference compared with $\mathrm{pFL},{ }^{*} p<0.05,{ }^{* *} p<0.001$

matter in pPL were significantly lower than that in pOL $(p<0.05, \mathrm{ES}=1.14)$ and higher than $\mathrm{dCO}(p<0.05, \mathrm{ES}=$ 1.16). MD of WMH in pPL were still significantly lower than that in $\mathrm{pOL}(p<0.001, \mathrm{ES}=1.90,1.12$ and 1.78), but were not significantly different with $\mathrm{dCO}$. AD of normal white matter and WMH in pPL were all significantly lower than that in pOL $(p<0.001, \mathrm{ES}=3.05,1.69$, 1.67 and 1.58), but were not significantly different with dCO except for the WMH with Fazekas scale $3(p<$ $0.001, \mathrm{ES}=1.30$ ). In normal controls, RD of pPL were significantly higher than that of $\mathrm{pOL}(p<0.001, \mathrm{ES}=$ $1.61)$ and $\mathrm{dCO}(p<0.001, \mathrm{ES}=2.38)$. RD of WMH with Fazekas scale 1 and 3 in pPL were significantly lower than that in $\operatorname{pOL}(p<0.05, \mathrm{ES}=1.31 ; p<0.001, \mathrm{ES}=$ 1.33). No significant difference was found in FA of WMH between pPL and $\mathrm{dCO}$.

\section{Discussion}

Correlation analysis revealed the relationship between DTI metrics and Fazekas scales. As expected, WMHs with higher Fazekas scale has lower FA, higher MD, AD and RD. These changes of DTI metrics may be caused by gliosis, demyelination, fluid accumulation and axonal loss among others [22]. However, some differences existed in the correlation coefficients of different regions, which means that WMH in different regions has certain heterogeneity.

Some studies have suggested that pathological differences exist between periventricular WMHs and deep WMHs [23-26]. Our results demonstrated that microstructural changes around the frontal periventricular WMHs were significantly different from those in other regions. There were significantly lower FA values, but higher $A D, R D$, and $M D$ values in frontal periventricular WMHs compared to other regions. As there were no such differences as indicated by the effect sizes in DTI metrics among different brain regions that featured normal white matter, therefore, these heterogeneities were likely not due to anatomical heterogeneities. These results underscore the pathological heterogeneity of WMHs in different regions. Previous studies with magnetization transfer imaging also showed a lower magnetization transfer ratio in frontal periventricular WMHs compared to parieto-occipital periventricular WMHs [19, 20]. Spilt et al. [19] suggested that age-related periventricular $\mathrm{WMH}$ around the frontal and occipital horns have different etiologies.

Some pathological studies suggested that periventricular WMHs occurred because of fluid accumulation within the extracellular space that was related to the loss of ventricular ependyma [27-29]. Although increases of interstitial water content might have led to significant increase in $\mathrm{MD}$, these changes could not explain the more immediate changes in RD values, compared to $\mathrm{AD}$ values. Our results showed that the decrease of FA and the increase of RD and $\mathrm{MD}$ in the periventricular WMHs were more significant than those in the other parts of WMHs. In the demyelinating animal model, the RD of the lesion was significantly higher than that of the normal white matter, while the $\mathrm{AD}$ was unchanged [30]. These uncoordinated changes in $\mathrm{AD}$ and $\mathrm{RD}$ were also observed in patient with multiple sclerosis [31]. Immunohistochemical findings also revealed that periventricular WMHs demonstrated more severe demyelination than deep WMHs [27]. A past neuropathological study found a stronger relationship

Table 5 Comparison of RD values $\left(\times 10^{-4} \mathrm{~mm}^{2} \mathrm{~s}^{-1}\right)$ of normal white matter or WMH with same Fazekas scale in different regions

\begin{tabular}{lllllll}
\hline & $\begin{array}{l}\text { pFL } \\
\text { Mean } \pm \text { SD }\end{array}$ & $\begin{array}{l}\text { pOL } \\
\text { Mean } \pm \text { SD }\end{array}$ & $\begin{array}{l}\text { pPL } \\
\text { Mean } \pm \text { SD }\end{array}$ & $\begin{array}{l}\text { dCO } \\
\text { Mean } \pm \text { SD }\end{array}$ & p-value & Effect Size (n2) \\
\hline Normal white matter & $3.63 \pm 0.79$ & $2.59 \pm 0.41^{* *}$ & $3.35 \pm 0.53$ & $2.33 \pm 0.30^{* *}$ & $<0.001$ & 0.531 \\
WMH of Fazekas scale 1 & $8.72 \pm 0.64$ & $5.86 \pm 1.05^{* *}$ & $4.66 \pm 0.50^{* *}$ & $5.31 \pm 0.80^{* *}$ & $<0.001$ & 0.795 \\
WMH of Fazekas scale 2 & $9.47 \pm 0.54$ & $5.89 \pm 1.07^{* *}$ & $5.23 \pm 1.16^{* *}$ & $5.79 \pm 0.57^{* *}$ & $<0.001$ & 0.820 \\
WMH of Fazekas scale 3 & $10.18 \pm 0.72$ & $7.33 \pm 1.18^{* *}$ & $5.88 \pm 1.00^{* *}$ & $6.52 \pm 0.79^{* *}$ & $<0.001$ & 0.723 \\
\hline
\end{tabular}

$p F L$ periventricular frontal lobe, $p O L$ periventricular occipital lobe, $p P L$ periventricular parietal lobe, $d C O$ deep centrum ovale. There was significant difference compared with $\mathrm{pFL},{ }^{*} p<0.05,{ }^{* *} p<0.001$ 

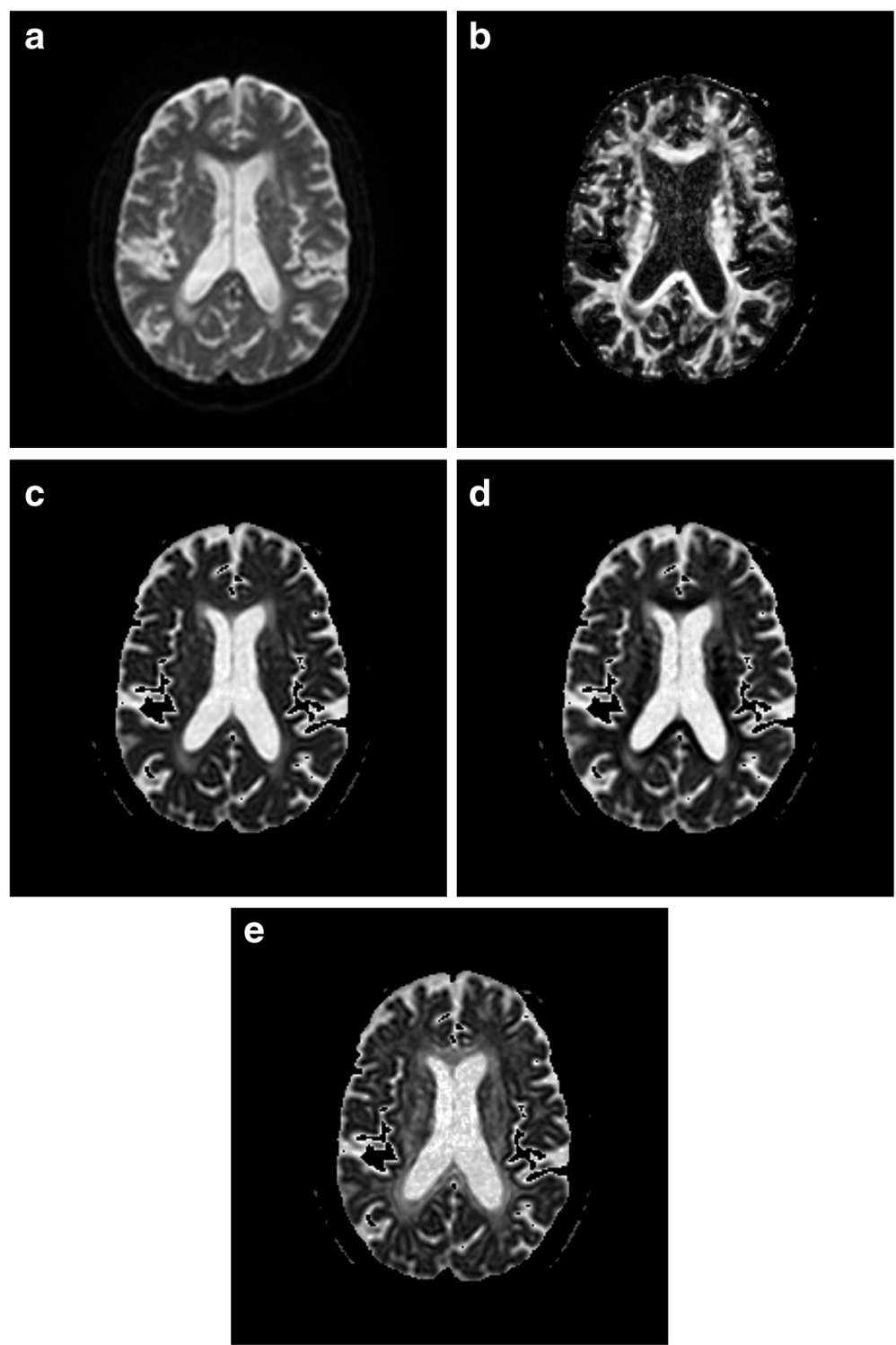

Fig. 8 The b0 of the DWI (a) of a 77 years old male showed WMH (Fazekas scale 2) in the pFL, pOH, pPL and dCO. FA (b) of WMH in the pFL are lower than that of $\mathrm{pOL}, \mathrm{pPL}$ and $\mathrm{dCO} . \mathrm{MD}(\mathbf{c})$ and $\mathrm{RD}(\mathbf{d})$ of $\mathrm{WMH}$ in the pFL are higher than that of $\mathrm{pOL}, \mathrm{pPL}$ and $\mathrm{dPCO}$. AD (e) of WMH in the $\mathrm{pFL}$ are close to that of $\mathrm{pOL}, \mathrm{pPL}$ and $\mathrm{dCO}$

between the extent of WMHs on MRI and the extent of myelin rarefaction in the frontal lobe, compared to the parietal lobe [32]. Another evidence is the lower T1-weighted signal of WMH around frontal horns [19], which is consistent with the "black hole" of demyelinating pathological changes [33]. Therefore, we believe that demyelination contributed to the pathological changes of frontal periventricular WMH. DTI, as a non-invasive technology, has the potential to classify WMH based on pathological changes, which will provide great value for future research.

Some studies [9-11] have elucidated links between cognitive decline and periventricular WMHs in the frontal lobe, parieto-occipital lobe, and other parts of the brain. However, the underlying pathological mechanisms of WMHs in different regions that might explain cognitive decline (other than anatomical locations) remain scarcely studied [9]. A recent DTI study [10] showed that, in patients with hypertension, anterior thalamic radiations, the superior longitudinal fasciculus, and the forceps minor had significantly lower FA and significantly higher $\mathrm{MD}, \mathrm{AD}$, and $\mathrm{RD}$ values; these changes corresponded with measures of cognitive impairment. In Duering's study [13] of cerebral autosomal dominant arteriopathy with subcortical infarcts and leukoencephalopathy (CADASIL), anterior thalamic radiations and 

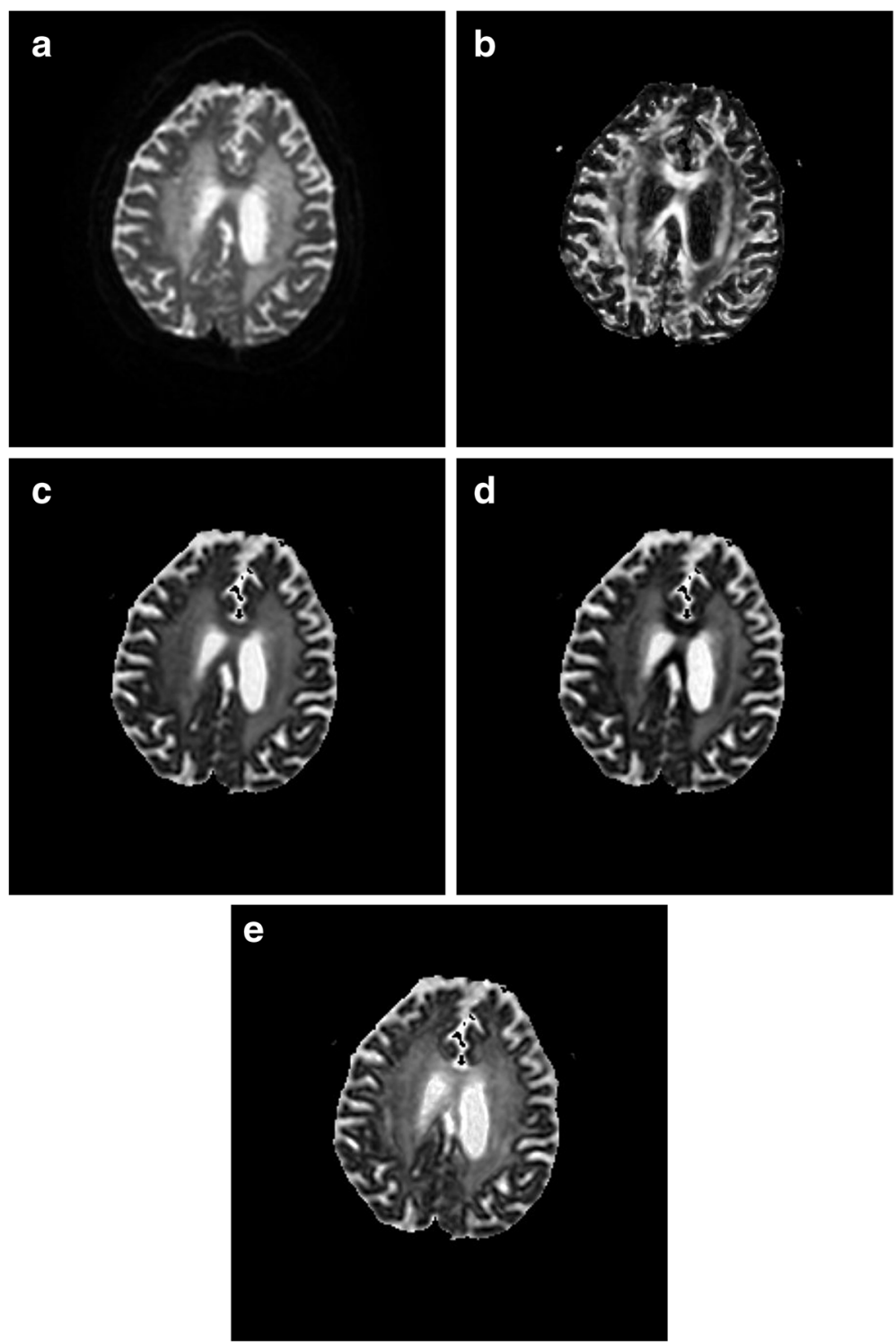

Fig. 9 The b0 of the DWI (a) of a 83 years old female showed WMH (Fazekas scale 3) in the pFL, pOL and dCO. FA (b) of WMH in the pFL are lower than that of $\mathrm{pPL}$ and $\mathrm{dCO} . \mathrm{MD}(\mathbf{c})$ and $\mathrm{RD}(\mathbf{d})$ of WMH in the pFL are higher than that of PPL and $\mathrm{dCO}$. AD (e) of WMH in the pFL are close to that of $\mathrm{PPL}$ and $\mathrm{dCO}$

frontal forceps were also considered key sites of cognitive impairment. These results suggested that frontal WMHs may contribute more to functional impairments. Frontal white matter microstructural changes began before the appearance of hyperintensities that could be found using conventional MRI. They appeared at an earlier age and demonstrated less age-related progression than WMHs in other regions [12]. This may lead to inconsistencies between the extent of WMHs and their respective pathological severities. The underlying pathological changes may be severe, even with little volumetric expansion. These findings suggested that even Fazekas grade $1 \mathrm{WMHs}$ around the frontal lateral ventricle may correspond to clinically significant pathological changes. We suggest that future studies should consider not only the volume of $\mathrm{WMH}$, but also their pathological severities.

Our study still has some limitations. First, normal white matter FA values decreased with age, while MD values increased with age. Average, our control group was significantly younger than patient group. However, the differences between WMHs and standard DTI metrics were greater than the normal variation observed with age [34]. We try to eliminate this effect by using age and gender as covariates. Second, to minimize the influence of DTI parameters caused by 
anatomical variations, we selected ROIs within identical white matter tracts, according to the color maps; however, variations may still exist for heterogeneity. Third, since the structural changes reflected by DTI parameters were non-specific and may have been affected by many factors, relevant pathological changes remain poorly elucidated. Fourth, the Fazekas classification method of WMH is not a quantitative evaluation method and may be affected by the different observer. However, the quantitative evaluation method is also limited by the division of ventricular and deep WMH and not a widely accepted approach [8].

\section{Conclusions}

Our results showed that pathological processes differed between frontal periventricular WMHs and WMHs of other regions. These differences may be due to more severe demyelination in the periventricular frontal white matter tracts. DTI has the potential to classify WMH based on pathological changes non-invasively. Future studies should consider pathological heterogeneity as a factor to better explore the relationships between WMHs and cognitive impairment.

\begin{abstract}
Abbreviations
WMHs: White matter hyperintensities; T2Wl: T2-weighted imaging; FLAl R: Fluid-attenuated inversion recovery; MRI: Magnetic resonance imaging; DTI: Diffusion tensor imaging; FA: Fractional anisotropy; MD: Mean diffusivity (MD); AD: Axial diffusivity; RD: Radial diffusivity; ROls: Regions of interest (ROls); pFL: Periventricular frontal lobe; pOL: Periventricular occipital lobe; pPL: Periventricular parietal lobe; dCO: Deep centrum ovale; CADA SIL: Cerebral autosomal dominant arteriopathy with subcortical infarcts and leukoencephalopathy
\end{abstract}

\section{Supplementary Information}

The online version contains supplementary material available at https://doi. org/10.1186/s12883-021-02140-9.

Additional file 1.

\section{Acknowledgements}

Not applicable.

\section{Authors' contributions}

ZM and HS performed statistical analysis, and were major contributor in writing the manuscript. LX, DY, XS and WX analyzed the clinical data and measured DTI metrics. HS and ZC assessed and grading WMH. MZ, CN and TMS contributed to editing and revising the manuscript. ZC contributed to editing and revising the manuscript and supervised this publication. All authors read and approved the final manuscript.

\section{Funding}

This work was supported by the Foundation of Medical and Health Guiding Projects of Science and Technology Development in Wuxi City (No. 32). The foundation provided financial support for data pooling, analysis and writing of the manuscript.

\section{Availability of data and materials}

All data generated or analysed during this study are included in this published article and its supplementary data files (Rawdata-rv2 .xIsx).

\section{Declarations}

Consent to publication

Not applicable.

\section{Ethics approval and consent to participate}

The Institutional Review Board of Affiliated Yixing Hospital of Jiangsu University approved this study. Written informed consent for participation was obtained from the patient.

\section{Competing interests}

The authors declare that they have no competing interests.

\section{Author details}

'Department of Radiology, The Affiliated Yixing Hospital of Jiangsu University, NO.75 Tongzhenguan Road, Yixing, Jiangsu Province 214200, P.R. China. ${ }^{2}$ Department of Radiology, First Affiliated Hospital of Xi'an Jiaotong University, Xi'an, Shaanxi Province, China.

Received: 14 July 2019 Accepted: 5 March 2021

Published online: 19 March 2021

\section{References}

1. de Leeuw FE, de Groot JC, Achten E, Oudkerk M, Ramos LM, Heijboer R, Hofman A, Jolles J, van Gijn J, Breteler MM. Prevalence of cerebral white matter lesions in elderly people: a population based magnetic resonance imaging study. The Rotterdam scan study. J Neurol Neurosurg Psychiatry. 2001;70(1):9-14. https://doi.org/10.1136/jnnp.70.1.9.

2. Gouw AA, Seewann A, van der Flier WM, Barkhof F, Rozemuller AM, Scheltens P, Geurts JJ. Heterogeneity of small vessel disease: a systematic review of MRI and histopathology correlations. J Neurol Neurosurg Psychiatry. 2011;82(2):126-35. https://doi.org/10.1136/jnnp.2009.204685.

3. Haller S, Kovari E, Herrmann FR, Cuvinciuc V, Tomm AM, Zulian GB, Lovblad KO, Giannakopoulos P, Bouras C. Do brain T2/FLAIR white matter hyperintensities correspond to myelin loss in normal aging? A radiologicneuropathologic correlation study. Acta neuropathologica communications. 2013;1(1):14. https://doi.org/10.1186/2051-5960-1-14

4. Prins ND, Scheltens $P$. White matter hyperintensities, cognitive impairment and dementia: an update. Nat Rev Neurol. 2015;11(3):157-65. https://doi. org/10.1038/nrneurol.2015.10.

5. Lin J, Wang D, Lan L, Fan Y. Multiple factors involved in the pathogenesis of white matter lesions. Biomed Res Int. 2017;2017:9372050.

6. Bos D, Wolters FJ, Darweesh SKL, Vernooij MW, de Wolf F, Ikram MA, Hofman A. Cerebral small vessel disease and the risk of dementia: a systematic review and meta-analysis of population-based evidence. Alzheimer's Dementia. 2018;14(11):1482-92. https://doi.org/10.1016/j.jalz.201 8.04.007.

7. Fazekas F, Chawluk JB, Alavi A, Hurtig HI, Zimmerman RA. MR signal abnormalities at 1.5 T in Alzheimer's dementia and normal aging. AJR Am J Roentgenol. 1987;149(2):351-6. https://doi.org/10.2214/ajr.149.2.351.

8. Kim KW, MacFall JR, Payne ME. Classification of white matter lesions on magnetic resonance imaging in elderly persons. Biol Psychiatry. 2008;64(4): 273-80. https://doi.org/10.1016/j.biopsych.2008.03.024.

9. Biesbroek JM, Weaver NA, Biessels GJ. Lesion location and cognitive impact of cerebral small vessel disease. Clinical science (London, England: 1979). 2017;131(8):715-28.

10. Carnevale L, D'Angelosante V, Landolfi A, Grillea G, Selvetella G, Storto M, Lembo G, Carnevale D. Brain MRI fiber-tracking reveals white matter alterations in hypertensive patients without damage at conventional neuroimaging. Cardiovasc Res. 2018;114(11):1536-46. https://doi.org/10.1 093/cvr/cvy104.

11. Cremers LG, de Groot M, Hofman A, Krestin GP, van der Lugt A, Niessen WJ, Vernooij MW, Ikram MA. Altered tract-specific white matter microstructure is related to poorer cognitive performance: the Rotterdam study. Neurobiol Aging. 2016;39:108-17. https://doi.org/10.1016/j.neurobiolaging.2015.11.021.

12. Habes M, Sotiras A, Erus G, Toledo JB, Janowitz D, Wolk DA, Shou H, Bryan NR, Doshi J, Volzke H, et al. White matter lesions: spatial heterogeneity, links to risk factors, cognition, genetics, and atrophy. Neurology. 2018;91(10): e964-75. https://doi.org/10.1212/WNL.0000000000006116.

13. Duering $M$, Zieren $N$, Herve $D$, Jouvent $E$, Reyes S, Peters N, Pachai $C$, Opherk C, Chabriat H, Dichgans M. Strategic role of frontal white matter 
tracts in vascular cognitive impairment: a voxel-based lesion-symptom mapping study in CADASIL. Brain : a journal of neurology. 2011;134(Pt 8): 2366-75. https://doi.org/10.1093/brain/awr169.

14. Griffanti L, Jenkinson M, Suri S, Zsoldos E, Mahmood A, Filippini N, Sexton CE, Topiwala A, Allan C, Kivimaki M, et al. Classification and characterization of periventricular and deep white matter hyperintensities on MRI: a study in older adults. Neurolmage. 2018;170:174-81. https://doi.org/10.1016/j. neuroimage.2017.03.024.

15. Bolandzadeh N, Davis JC, Tam R, Handy TC, Liu-Ambrose T. The association between cognitive function and white matter lesion location in older adults: a systematic review. BMC Neurol. 2012;12(1):126. https://doi.org/10.11 86/1471-2377-12-126

16. de Laat KF, van Norden AG, van Oudheusden LJ, van Uden IW, Norris DG, Zwiers MP, de Leeuw FE. Diffusion tensor imaging and mild parkinsonian signs in cerebral small vessel disease. Neurobiol Aging. 2012;33(9):2106-12. https://doi.org/10.1016/j.neurobiolaging.2011.09.001.

17. van Norden AG, de Laat KF, van Dijk EJ, van Uden IW, van Oudheusden LJ, Gons RA, Norris DG, Zwiers MP, de Leeuw FE. Diffusion tensor imaging and cognition in cerebral small vessel disease: the RUN DMC study. Biochim Biophys Acta. 2012;1822(3):401-7. https://doi.org/10.1016/j.bbadis.2011.04.008.

18. van Leijsen EMC, Bergkamp MI, van Uden IWM, Ghafoorian M, van der Holst HM, Norris DG, Platel B, Tuladhar AM, de Leeuw FE. Progression of white matter Hyperintensities preceded by heterogeneous decline of microstructural integrity. Stroke. 2018;49(6):1386-93. https://doi.org/10.1161/ STROKEAHA.118.020980.

19. Spilt A, Goekoop R, Westendorp RG, Blauw GJ, de Craen AJ, van Buchem MA. Not all age-related white matter hyperintensities are the same: a magnetization transfer imaging study. AJNR Am J Neuroradiol. 2006;27(9): 1964-8.

20. Bastin ME, Clayden JD, Pattie A, Gerrish IF, Wardlaw JM, Deary IJ. Diffusion tensor and magnetization transfer MRI measurements of periventricular white matter hyperintensities in old age. Neurobiol Aging. 2009;30(1):12536. https://doi.org/10.1016/j.neurobiolaging.2007.05.013.

21. Jiang H, van Zijl PC, Kim J, Pearlson GD, Mori S. DtiStudio: resource program for diffusion tensor computation and fiber bundle tracking. Comput Methods Prog Biomed. 2006;81(2):106-16. https://doi.org/10.1016/..cmpb.2 005.08.004.

22. Beaulieu C. The basis of anisotropic water diffusion in the nervous system a technical review. NMR Biomed. 2002;15(7-8):435-55. https://doi.org/10.1 $002 / \mathrm{nbm} .782$

23. Valdes Hernandez MC, Piper RJ, Bastin ME, Royle NA, Maniega SM, Aribisala BS, Murray C, Deary IJ, Wardlaw JM. Morphologic, distributional, volumetric, and intensity characterization of periventricular hyperintensities. AJNR Am J Neuroradiol. 2014;35(1):55-62. https://doi.org/10.3174/ajnr.A3612.

24. Anderson VC, Obayashi JT, Kaye JA, Quinn JF, Berryhill P, Riccelli LP, Peterson D, Rooney WD. Longitudinal relaxographic imaging of white matter hyperintensities in the elderly. Fluids and barriers of the CNS. 2014; 11(1):24. https://doi.org/10.1186/2045-8118-11-24

25. Murray ME, Vemuri P, Preboske GM, Murphy MC, Schweitzer KJ, Parisi JE, Jack CR Jr, Dickson DW. A quantitative postmortem MRI design sensitive to white matter hyperintensity differences and their relationship with underlying pathology. J Neuropathol Exp Neurol. 2012;71(12):1113-22. https://doi.org/10.1097/NEN.0b013e318277387e.

26. Stenset V, Hofoss D, Berstad AE, Negaard A, Gjerstad L, Fladby T. White matter lesion subtypes and cognitive deficits in patients with memory impairment. Dement Geriatr Cogn Disord. 2008;26(5):424-31. https://doi. org/10.1159/000165355.

27. Simpson JE, Fernando MS, Clark L, Ince PG, Matthews F, Forster G, O'Brien JT, Barber R, Kalaria RN, Brayne C, Shaw PJ, Lewis CE, Wharton SB, MRC Cognitive Function and Ageing Neuropathology Study Group. White matter lesions in an unselected cohort of the elderly: astrocytic, microglial and oligodendrocyte precursor cell responses. Neuropathol Appl Neurobiol. 2007;33(4):410-9. https://doi.org/10.1111/j.1365-2990.2007.00828.x.

28. O'Sullivan M. Leukoaraiosis. Pract Neurol. 2008;8(1):26-38. https://doi.org/1 0.1136/jnnp.2007.139428

29. Fernando MS, Simpson JE, Matthews F, Brayne C, Lewis CE, Barber R, Kalaria RN, Forster G, Esteves F, Wharton SB, Shaw PJ, O'Brien JT, Ince PG, MRC Cognitive Function and Ageing Neuropathology Study Group. White matter lesions in an unselected cohort of the elderly: molecular pathology suggests origin from chronic hypoperfusion injury. Stroke. 2006:37(6):13918. https://doi.org/10.1161/01.STR.0000221308.94473.14.
30. Song SK, Sun SW, Ramsbottom MJ, Chang C, Russell J, Cross AH. Dysmyelination revealed through MRI as increased radial (but unchanged axial) diffusion of water. Neurolmage. 2002;17(3):1429-36. https://doi.org/1 $0.1006 /$ nimg.2002.1267.

31. Roosendaal SD, Geurts JJ, Vrenken H, Hulst HE, Cover KS, Castelijns JA, Pouwels PJ, Barkhof F. Regional DTI differences in multiple sclerosis patients. Neurolmage. 2009;44(4):1397-403. https://doi.org/10.1016/j.neuroimage.2 008.10.026.

32. Smith CD, Snowdon D, Markesbery WR. Periventricular white matter hyperintensities on MRI: correlation with neuropathologic findings. $J$ Neuroimaging. 2000;10(1):13-6. https://doi.org/10.1111/jon200010113.

33. Naismith RT, Xu J, Tutlam NT, Scully PT, Trinkaus K, Snyder AZ, Song SK, Cross AH. Increased diffusivity in acute multiple sclerosis lesions predicts risk of black hole. Neurology. 2010;74(21):1694-701. https://doi.org/10.1212/ WNL.0b013e3181e042c4.

34. Abe O, Aoki S, Hayashi N, Yamada H, Kunimatsu A, Mori H, Yoshikawa T, Okubo T, Ohtomo K. Normal aging in the central nervous system: quantitative MR diffusion-tensor analysis. Neurobiol Aging. 2002;23(3):43341. https://doi.org/10.1016/S0197-4580(01)00318-9.

\section{Publisher's Note}

Springer Nature remains neutral with regard to jurisdictional claims in published maps and institutional affiliations.
Ready to submit your research? Choose BMC and benefit from:

- fast, convenient online submission

- thorough peer review by experienced researchers in your field

- rapid publication on acceptance

- support for research data, including large and complex data types

- gold Open Access which fosters wider collaboration and increased citations

- maximum visibility for your research: over $100 \mathrm{M}$ website views per year

At $\mathrm{BMC}$, research is always in progress.

Learn more biomedcentral.com/submissions 